\title{
“An Unbalanced Diet Limited to the Consumption of Boiled Vegetables Led to the Onset of Scurvy."
}

\author{
Kenta Hayashino, Yusuke Meguri, Aya Komura, Chisato Matsubara, Yutarou Shiraishi, \\ Chikamasa Yoshida, Kazuhiko Yamamoto and Kenji Imajo
}

\begin{abstract}
:
Scurvy is a rare disease caused by a vitamin C deficiency. Vitamin C is a water-soluble vitamin found in vegetables and fruits, but it is lost after boiling. A 59-year-old man presented with gingival pain after having a tooth extracted five years previously. Following the procedure, his diet comprised boiled vegetables to prevent pain. He then experienced bilateral lower leg pain, and computed tomography revealed intramuscular bleeding. His serum vitamin $\mathrm{C}$ level was below the detectable limit. His symptoms immediately improved with vitamin $\mathrm{C}$ administration. This case emphasized that consuming only boiled vegetables can lead to the onset of scurvy.
\end{abstract}

Key words: scurvy, vitamin C deficiency, boiled vegetables

(Intern Med Advance Publication)

(DOI: 10.2169/internalmedicine.8122-21)

\section{Introduction}

Scurvy is a rare disease among developed countries, where most foods are nutritious and provide adequate vitamin C. However, it can occur in psychiatric, alcoholic, socially isolated, elderly, or homeless patients (1-3). Its early symptoms are fatigue, followed by perifollicular hemorrhaging, leg edema, poor wound healing, gingival overgrowth, purpura, and ecchymosis (3). Scurvy is challenging to diagnose because of its rarity, and because its clinical symptoms are similar to those of disorders such as vasculitis and bleeding diatheses, such as hemophilia (4). Scurvy symptoms promptly improve and disappear within days to weeks after replenishing vitamin $\mathrm{C}$ (5).

Vitamin $\mathrm{C}$ is not synthesized in the human body, so humans require exogenous sources. The body pool of vitamin $\mathrm{C}$ is approximately $1,500 \mathrm{mg}$. This patient's clinical symptoms emerged when his vitamin C levels fell below 300 mg (6). The "Dietary Reference Intakes for Japanese (2020)," presented by the Ministry of Health, Labour and Welfare, recommended taking $100 \mathrm{mg} /$ day of vitamin $\mathrm{C}$ to prevent cardiovascular events and it also acts as antioxidant (7). The amount of vitamin $\mathrm{C}$ required to prevent scurvy is equal to the dosage needed to treat scurvy at 10 $\mathrm{mg} /$ day (8). Vitamin C, a water-soluble found in vegetables and fruits, however, it is lost after boiling (9). We herein present the case of a 59-year-old man with scurvy. He had a regular diet until he experienced ginggrivaml pain after having a tooth extracted five years previously, following which, he only ate boiled foods.

\section{Case Presentation}

A 59-year-old man presented to the emergency department with bilateral lower leg pain and swelling for one week. He experienced fatigue for five months and frequent nasal bleeding for two months. His medical history included retinal detachment and appendicitis when he was 30 years old. He had an eccentric character but was never diagnosed with any mental health disorder. He did not smoke or drink alcohol, and took no medication. He did not have a low socioeconomic status. He had no family history of hemophilia. He was $182 \mathrm{~cm}$ tall and, weighed $57.6 \mathrm{~kg}$, and his body mass index was $17.4 \mathrm{~kg} / \mathrm{m}^{2}$. He had pain, ecchymosis, and edema in both lower legs, with his left leg being worse than the right (Fig. 1). A coagulation study revealed normocytic anemia and mild disorders. Computed tomography showed 

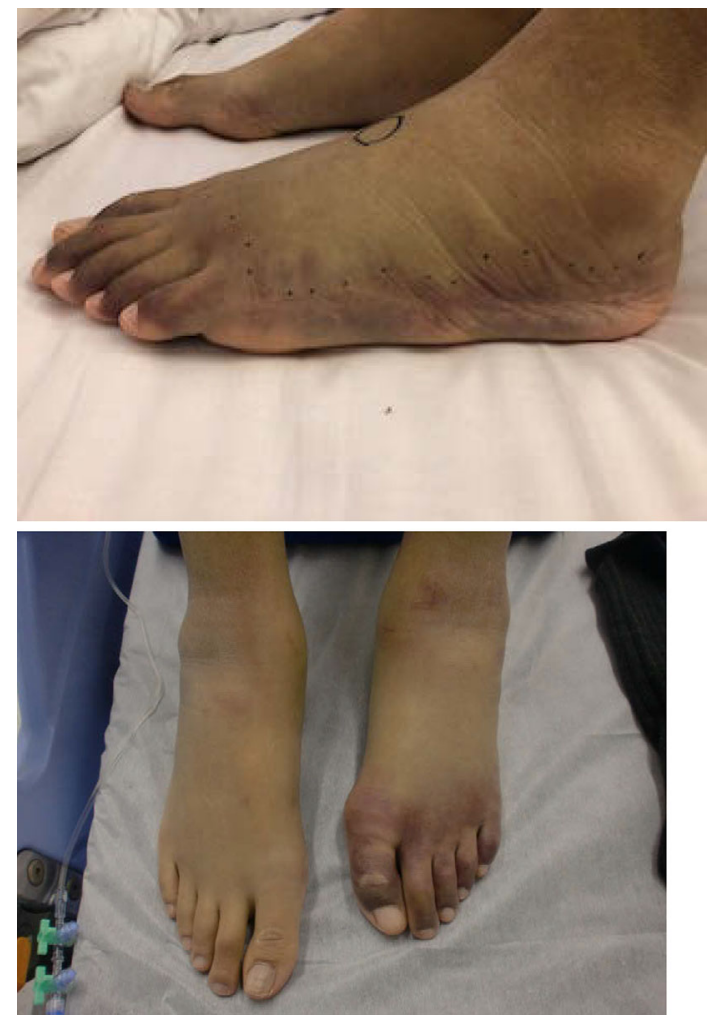

Figure 1. Ecchymosis, and edema in his both lower legs. bilateral biceps femoris, tibialis anterior, and peroneal muscle bleeding (Fig. 2). He suffered from gingival pain after a tooth extraction five years previously. After the procedure, he avoided eating foods stimulating the gingiva. He limited his diet to boiled rice $(300 \mathrm{~g})$, natto $(100 \mathrm{~g})$, tofu $(150 \mathrm{~g})$, and fish sausage $(90 \mathrm{~g})$, which have no vitamin $\mathrm{C}$ at all, and boiled vegetables (70-140 g) which contain 14.5 (4.8-24.2) $\mathrm{mg}$ vitamin $\mathrm{C}$. He consumed boiled vegetables including carrots, broccoli, cabbage, Chinese cabbage, green onions, and onions. He did not consume fruit, fish, or meat to prevent pain, and he also avoided instant foods, which reportedly contain several vitamins. His gingival pain improved two years ago, but he did not change his diet because he became accustomed to it. His serum vitamin $C$ level was significantly low $(<0.2 \mu \mathrm{g} / \mathrm{mL})$, and he was diagnosed with scurvy. The serum levels of vitamin A, vitamin B1, folic acid, and zinc were also slightly low (Table 1).

After the diagnosis, he received a multivitamin drip comprising vitamin C (200 mg/day), followed by daily oral multivitamin tablets, including vitamin $\mathrm{C}(600 \mathrm{mg} / \mathrm{day})$. The pain, ecchymosis, and edema notably improved within a few days, and serum vitamin $\mathrm{C}$ levels normalized two weeks after treatment.
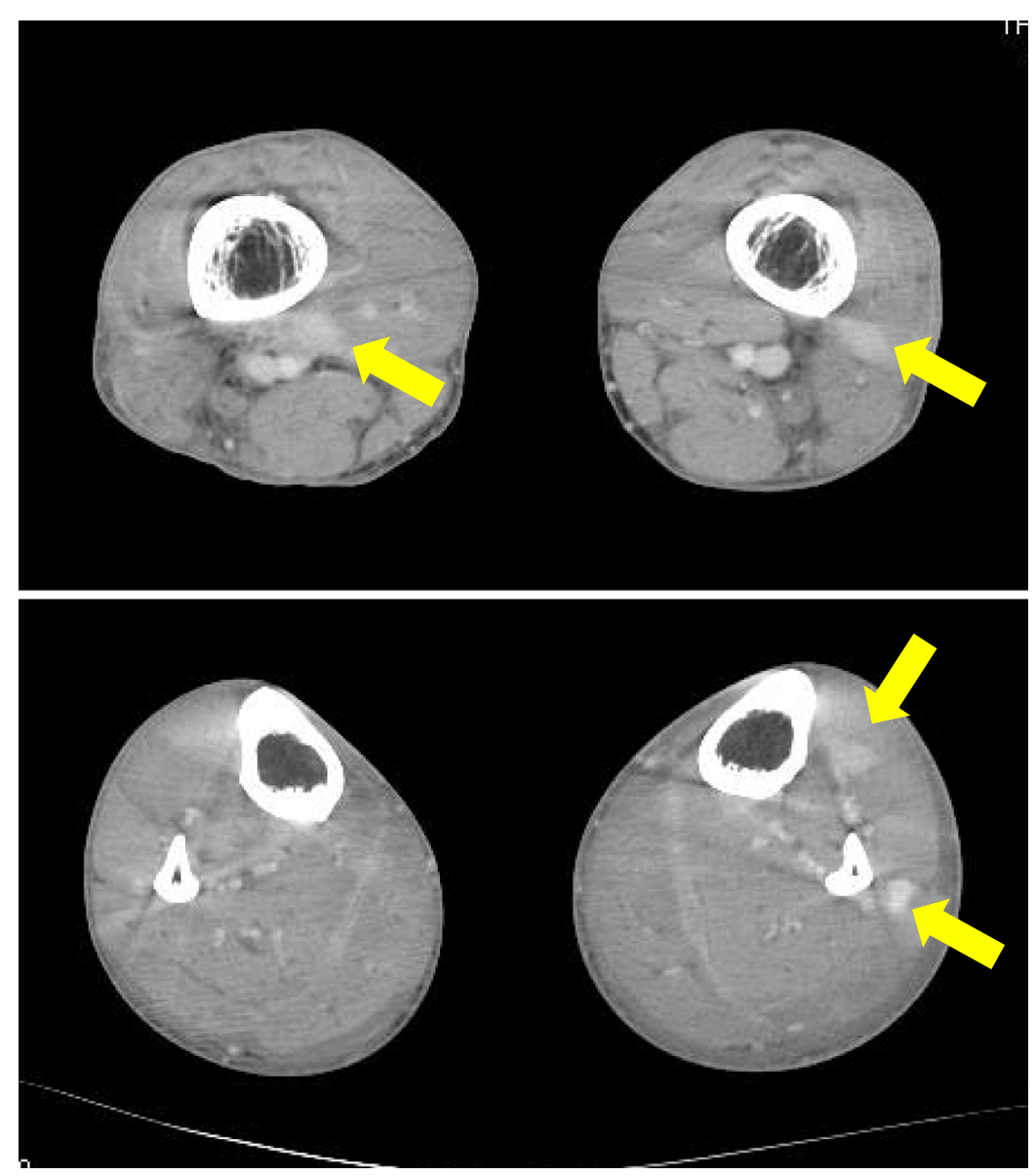

Figure 2. CT scan showed contrast media leaking in the bilateral biceps femoris, tibialis anterior, and peroneal muscle. 


\section{Discussion}

Vitamin $\mathrm{C}$ is present in fruits and vegetables, and their inadequate consumption results in scurvy. Typical scurvy cases involve patients who refuse to ingest fruits and vegetables $(4,10-12)$. However, this patient ate vegetables daily.

Table 1. Laboratory Date on Admission.

\begin{tabular}{|c|c|c|}
\hline Parameter(unit) & First visit & Standard level \\
\hline $\mathrm{WBC}(/ \mu \mathrm{L})$ & 5,750 & $3,300-8,600$ \\
\hline $\mathrm{Hb}(\mathrm{mg} / \mathrm{dL})$ & 7.8 & $13.7-16.8$ \\
\hline $\mathrm{HCT}(\%)$ & 23.6 & $40.7-50.1$ \\
\hline MCV(fL) & 91.5 & $83.6-98.2$ \\
\hline $\operatorname{PLT}\left(\times 10^{\wedge} 3 / \mu \mathrm{L}\right)$ & 173 & $158-348$ \\
\hline $\mathrm{PT}(\%)$ & 67 & $70-130$ \\
\hline APTT(sec) & 33.2 & $26.9-38.1$ \\
\hline D-Dimer $(\mu \mathrm{g} / \mathrm{mL})$ & 2.3 & $<1.0$ \\
\hline Fibrinogen(mg/dL) & 356 & $200-400$ \\
\hline $\mathrm{TAT}(\mathrm{ng} / \mathrm{mL})$ & 3.1 & $<3.0$ \\
\hline $\operatorname{PIC}(\mu \mathrm{g} / \mathrm{mL})$ & 0.5 & $<0.8$ \\
\hline FXIII(\%) & 51 & $\leq 70$ \\
\hline $\mathrm{TP}(\mathrm{mg} / \mathrm{dL})$ & 6.0 & $6.6-8.1$ \\
\hline $\operatorname{Alb}(\mathrm{mg} / \mathrm{dL})$ & 3.4 & $4.1-5.1$ \\
\hline AST(IU/L) & 15 & $13-30$ \\
\hline ALT(IU/L) & 6 & $10-42$ \\
\hline T-Bil(mg/dL) & 2.23 & $0.4-1.5$ \\
\hline $\mathrm{BUN}(\mathrm{mg} / \mathrm{dL})$ & 23 & $8-20$ \\
\hline $\operatorname{Cre}(\mathrm{mg} / \mathrm{dL})$ & 1.01 & $0.65-1.07$ \\
\hline Vitamin $\mathrm{C}(\mu \mathrm{g} / \mathrm{mL})$ & $<2.0$ & $5.5-16.8$ \\
\hline Vitamin $\mathrm{B} 1(\mu \mathrm{g} / \mathrm{dL})$ & 1.7 & $2.6-5.8$ \\
\hline Foliamine(ng/mL) & 2.3 & $3.6-12.9$ \\
\hline Vitamin B12(pg/mL) & 270 & 233-914 \\
\hline $\mathrm{Zn}(\mathrm{mg} / \mathrm{dL})$ & 54 & $80-130$ \\
\hline
\end{tabular}

The minimal daily requirement of vitamin $\mathrm{C}$ to prevent scurvy is only $10 \mathrm{mg}$ or less (7). In this case, his daily diet consisted of rice, natto, tofu, and fish sausage, which provided inadequate amounts of vitamin $\mathrm{C}$. He consumed approximately 70-140 $\mathrm{g}$ of vegetables, which were boiled for 40-50 minutes. Vitamin $\mathrm{C}$ is a water-soluble vitamin, and in vegetables, approximately $50-80 \%$ is lost after boiling (9). His diet and the amount of vitamin $\mathrm{C}$ are shown in Table 2. His caloric intake was less than the recommendation of Dietary Reference Intakes for Japanese (2020). If the patient did not boil the vegetables, he would have ingested 24.2-48.6 $\mathrm{mg}$ of vitamin $\mathrm{C}$ per day. However, he only ingested approximately $4.8-24.2 \mathrm{mg}$ of vitamin $\mathrm{C}$ per day due to boiling.

Additionally, he stored these boiled vegetables in his refrigerator for a few days and heated them in the microwave before eating. Vitamin $\mathrm{C}$ is also lost in foods that are stored then heated. The storage method of foods is also important for preventing scurvy; for example, refrigerated food loses more vitamin C than frozen food (10). Recently pre-cooked and chilled under the new cook-chill system are adopted in many hospitals, scurvy is not common among in-hospital patients. The symptoms of scurvy appear 29-90 days after complete deprivation of vitamin C (6). Some cases exhibit an indolent disease course, developing over five to 10 years $(4,11-13)$, wherein the vitamin $\mathrm{C}$ deficit is only partial. In our case, the patient maintained minimal amounts of vitamin $\mathrm{C}$ for five years, which resulted in the indolent course of scurvy. Scurvy prevention involves prescribing sufficient vitamin $\mathrm{C}$ intake through multivitamin supplementation and dietary modification.

The various treatment regimens for scurvy include oral multivitamins (vitamin C $60 \mathrm{mg}$ ) for 10 days (4); vitamin C (100 mg) three times a day (3); and vitamin C (1-2 g) daily

Table 2. Vitamin C Contents of the Patient Diets.

\begin{tabular}{|c|c|c|c|c|c|}
\hline Food name & *Total weight(g) & $\begin{array}{l}\text { Density of vitamin C } \\
(\mathrm{mg} / 100 \mathrm{~g})\end{array}$ & $\begin{array}{l}\text { Weight of Vitamin } \\
\text { C(raw)(mg/day) }\end{array}$ & $\begin{array}{l}\text { Weight of Vitamin } \\
\text { C(boiled)(mg/day) }\end{array}$ & Energy (kcal) \\
\hline boiled rice & 300 & 0 & 0 & 0 & 1,060 \\
\hline natto & 100 & 0 & 0 & 0 & 200 \\
\hline tofu & 150 & 0 & 0 & 0 & 120 \\
\hline fish sausage & 90 & 0 & 0 & 0 & 160 \\
\hline Total & & & & & 1,540 \\
\hline \multicolumn{6}{|c|}{ Chopped vegetables paste } \\
\hline carrot & $17.6(11.7-23.4)$ & 6 & $1.1(0.7-1.4)$ & $0.4(0.1-0.7)$ & \\
\hline broccoli & $17.6(11.7-23.4)$ & 120 & $21(14-28)$ & $8.4(2.8-14)$ & \\
\hline cabbage & $17.6(11.7-23.4)$ & 41 & $7.2(4.8-9.6)$ & $2.9(1-4.8)$ & \\
\hline Chinese cabbage & $17.6(11.7-23.4)$ & 19 & $3.3(2.2-4.4)$ & $1.3(0.4-2.2)$ & \\
\hline green onion & $17.6(11.7-23.4)$ & 14 & $2.5(1.6-3.3)$ & $1.0(0.3-1.6)$ & \\
\hline onion & $17.6(11.7-23.4)$ & 8 & $1.4(0.9-1.9)$ & $0.6(0.2-0.9)$ & \\
\hline Total & $70-140$ & & $36.4(24.2-48.6)$ & $14.5(4.8-24.2)$ & \\
\hline
\end{tabular}

*Total weight of foods is presented by mean value and range of maximum and minimum value based on the self-assessment of this patient. His daily food is the chopped vegetable paste which equally includes these vegetables and he had eaten that one or two small bowls per a day. Wight of vitamin C and energy are calculated with reference to the "Standard Tables of Food Composition in Japan (2020)". 
for the first two to three days, followed by $500 \mathrm{mg}$ per day for the next week, and $100 \mathrm{mg}$ per day for one to three months (14). Scurvy symptoms usually improve within a few days. In this case, $200 \mathrm{mg}$ of vitamin C was administered intravenously daily for the first one to four days, followed by oral multivitamin supplementation (vitamin C 600 mg per day). His leg pain, swelling, purpura, and anemia all improved within two weeks.

\section{Conclusion}

This case emphasized that while vegetables provide vitamin $\mathrm{C}$, boiling significantly reduces this, thereby resulting in scurvy.

The authors state that they have no Conflict of Interest (COI).

\section{Acknowledgement}

The authors would like to thank the patient and medical staff for their contributions to the case report.

\section{Ethical Publication Statement}

We confirm that we have read the Journal's position on issues involved in ethical publication and affirm that this report is consistent with those guidelines. This study has been approved by the research ethics committee of Okayama City Hospital.

\section{References}

1. Shaikh H, Faisal MS, Mewawalla P. Vitamin C deficiency: rare cause of severe anemia with hemolysis. Int J Hematol 109: 618621, 2019.

2. Doll S, Ricou B. Severe vitamin C deficiency in a critically ill adult: A case report. Eur J Clin Nutr 67: 881-882, 2013.

3. Hirschmann JV, Raugi GJ. Adult scurvy. J Am Acad Dermatol 41: 895-906, 1999.

4. Stephen R, Utecht T. Scurvy identified in the emergency department: A case report. J Emerg Med 21: 235-237, 2001.

5. Khalife R, Grieco A, Khamisa K, Tinmouh A, McCudden C, Saidenberg E. Scurvy, an old story in a new time: The hematologist's experience. Blood Cells, Mol Dis 76: 40-44, 2019.

6. Hodges RE, Baker EM, Hood J, Sauberlich HE, March SC. Experimental scurvy in man. Am J Clin Nutr 22: 535-548, 1969.

7. Gey KF. Vitamins $E$ plus $C$ and interacting conutrients required for optimal health. A critical and constructive review of epidemiology and supplementation data regarding cardiovascular disease and cancer. Biofactors 7: 113-174, 1998.

8. Hodges RE, Hood J, Canham JE, Sauberlich HE, Baker EM. Clinical manifestations of ascorbic acid deficiency in man. Am J Clin Nutirtion 24: 432-443, 1971.

9. Levine M, Rumsey SC, Daruwala R, Park JB, Wang Y. Criteria and recommendations for vitamin C intake. J Am Med Assoc 281: 1415-1423, 1999.

10. Bouzari A, Holstege D, Barrett DM. Vitamin retention in eight fruits and vegetables: A comparison of refrigerated and frozen storage. J Agric Food Chem 63: 957-962, 2015.

11. El Khoury R, Warren M, Ali S, Pirkle JL. An Unexpected Case of Scurvy in a Peritoneal Dialysis Patient. Case Reports Nephrol Dial 7: 172-177, 2017.

12. Ferreira CCG, de Sá Pereira Belfort D, , Neto PMC, Gouveia PA da C. Reversible Pulmonary Hypertension Secondary to Scurvy in a Patient with a Psychiatric Disorder: a Case Report and Literature Review. Eur J Case Reports Intern Med 7: 001404, 2020.

13. Lipner S. A classic case of scurvy. Lancet 392: 431, 2018.

14. Léger D. Scurvy: Reemergence of nutritional deficiencies. Can Fam Physician 54: 1403-1406, 2008.

The Internal Medicine is an Open Access journal distributed under the Creative Commons Attribution-NonCommercial-NoDerivatives 4.0 International License. To view the details of this license, please visit (https://creativecommons.org/licenses/ by-nc-nd/4.0/).

(C) The Japanese Society of Internal Medicine Intern Med Advance Publication 